\title{
A Methodology for Assessing Eco-Efficiency in Logistics Networks
}

\section{J. Quariguasi Frota Neto, G. Walther, J.Bloemhof, J.A.E.E van Nunen and T.Spengler}

\begin{tabular}{|l|l|}
\hline \multicolumn{2}{|l|}{ ERIM REPORT SERIES RESEARCH IN MANAGEMENT } \\
\hline ERIM Report Series reference number & ERS-2007-037-LIS \\
\hline Publication & May 2007 \\
\hline Number of pages & 33 \\
\hline Persistent paper URL & \\
\hline Email address corresponding author & jquariguasi@rsm.nl \\
\hline Address & Erasmus Research Institute of Management (ERIM) \\
& RSM Erasmus University / Erasmus School of Economics \\
& Erasmus Universiteit Rotterdam \\
& P.O.Box 1738 \\
& 3000 DR Rotterdam, The Netherlands \\
& Phone: + 31 10 4081182 \\
& Fax: +31 104089640 \\
& Email: info@erim.eur.nl \\
& Internet: www.erim.eur.nl \\
\hline
\end{tabular}

Bibliographic data and classifications of all the ERIM reports are also available on the ERIM website: www.erim.eur.nl 


\section{ERASMUS RESEARCH INSTITUTE OF MANAGEMENT}

\section{REPORT SERIES}

\section{RESEARCH IN MANAGEMENT}

\begin{tabular}{|c|c|}
\hline \multicolumn{2}{|c|}{ ABSTRACT AND KEYWORDS } \\
\hline Abstract & $\begin{array}{l}\text { Recent literature on sustainable logistics networks points to two important questions: (i) How to } \\
\text { spot the preferred solution(s) balancing environmental and business concerns? (ii) How to } \\
\text { improve the understanding of the trade-offs between these two dimensions? We posit that a } \\
\text { complete exploration of the efficient frontier and trade-offs between profitability and } \\
\text { environmental impacts are particularly suitable to answer these two questions. In order to deal } \\
\text { with the exponential number of basic efficient points in the frontier, we propose a formulation that } \\
\text { performs in exponential time for the number of objective functions only. We illustrate our findings } \\
\text { by designing a complex recycling logistics network in Germany. }\end{array}$ \\
\hline Free Keywords & Eco-efficiency, Sustainable logistics networks, Environmental impacts, Complex recycling \\
\hline Availability & $\begin{array}{l}\text { The ERIM Report Series is distributed through the following platforms: } \\
\text { Academic Repository at Erasmus University (DEAR), DEAR ERIM Series Portal } \\
\text { Social Science Research Network (SSRN), SSRN ERIM Series Webpage } \\
\text { Research Papers in Economics (REPEC), REPEC ERIM Series Webpage }\end{array}$ \\
\hline Classifications & $\begin{array}{l}\text { The electronic versions of the papers in the ERIM report Series contain bibliographic metadata } \\
\text { by the following classification systems: } \\
\text { Library of Congress Classification, (LCC) LCC Webpage } \\
\text { Journal of Economic Literature, (JEL), JEL Webpage } \\
\text { ACM Computing Classification System CCS Webpage } \\
\text { Inspec Classification scheme (ICS), ICS Webpage }\end{array}$ \\
\hline
\end{tabular}




\title{
A methodology for assessing eco-efficiency in logistics
}

\section{networks}

\author{
J. Quariguasi Frota Neto ${ }^{1 *}$, G. Walther ${ }^{2}$, \\ J. Bloemhof ${ }^{1}$, J.A.E.E van Nunen ${ }^{1}$, T. Spengler ${ }^{2}$ \\ ${ }^{1}$ Rotterdam School of Management (RSM), Erasmus University, The Netherlands \\ ${ }^{2}$ Braunschweig Technical University, Institute for Economics and Business Administration, Germany
}

May 9, 2007

\begin{abstract}
Recent literature on sustainable logistics networks points to two important questions: (i) How to spot the preferred solution(s) balancing environmental and business concerns? (ii) How to improve the understanding of the trade-offs between these two dimensions? We posit that a complete exploration of the efficient frontier and trade-offs between profitability and environmental impacts are particularly suitable to answer these two questions. In order to deal with the exponential number of basic efficient points in the frontier, we propose a formulation that performs in exponential time for the number of objective functions only. We illustrate our findings by designing a complex recycling logistics network in Germany.
\end{abstract}

\section{Introduction}

In the past years, consumers, companies and governments have increased their attention towards the environment. In fact, our entire society is more aware of environmental damage caused by human actions due to increased exposure in the media on e.g. global warming and depletion of natural resources. Companies invest more in the assessment and reduction of the environmental impact of their products and services. IBM, for instance, promotes the take-back, recycling,

*corresponding author. Rotterdam School of Management, Erasmus University, PO Box 1738, 3000DR , Rotterdam, The Netherlands. jquariguasi@rsm.nl 
refurbishing and re-use of its computers (Fleischmann et al. [2003]). Governments have changed the "end-of-pipe" environmental laws to more comprehensive ones, broadening the responsibility of producers towards a "cradle-to-grave" perspective. The European Union, for instance, has approved the Waste Electrical and Electronic Equipment (WEEE) directive, making producers responsible for their end-of-life products.

Improvement in environmental quality does not come for free. The win-win solutions for business and the environment seem quite elusive in practice, in particular for considerable reductions in environmental impacts (Walley and Whitehead [1994]). The popular saying "there is no such a thing as a free lunch" could not be more true in this case. In the sphere of the "no free lunch" paradigm, some questions should be posed: How much do we have to spend in order to improve environmental quality? Or in more scientific terms, which trade-offs occur between the environmental impacts of an economic activity and its costs? And, what are "best" solutions balancing ecological and economic concerns? (Quariguasi Frota Neto et al. [2007]).

In the normative and qualitative field, these questions have led to the concept of trade-offs and efficient frontiers for business and the environment (Huppes and Ishikawa [2005], Bloemhof-Ruwaard et al. [2004]). The rationale is to determine the set of solutions in which it is not possible to decrease environmental damage, or increase total environmental quality of each environmental category, unless increasing costs. These solutions are called eco-efficient. The idea of exploring the best alternatives is based on Pareto Optimality. The Pareto optimal frontier (the efficient frontier is composed by the set of the images of all efficient solutions in relation to the objectives: optimize economical and environmental goals. Figure 1 illustrates the efficient frontier and the trade-offs. The axes represent the indices of the economic value and the environmental quality of an economic activity. The curve represents the efficient frontier, where one cannot decrease either the environmental pressure without decreasing the economic value added (Kuosmanen and Kortelainen [2005]). The area below the curve is eco-eco inefficient: it is feasible to increase economic value without restricting environmental quality or the other way round. We assume that the actual situation represents an inefficient solution. This solution can be improved by moving 
to the efficient frontier. As each point on the efficient frontier is Pareto optimal, it is up to the decision maker which improvement path is preferable. Increasing environmental quality without losing economic value means moving to the right, increasing economic value without losing environmental quality means moving up. The trade-off line is chosen by society.

\section{insert figure 1}

From a methodological perspective, determining such an efficient frontier or assessing the tradeoffs in logistic networks is quite new, despite the extensive existing literature in the field of multiobjective programming (MOP). We intend to bridge this gap by an approach that is sounded to capitalize the decision maker's most effective cognitive capabilities: visual representation. In order to explore the efficient frontier in feasible CPU-time, we develop a new algorithm exploring the Pareto frontier for multi-objective linear programming (MOLP) problems in which CPU-time grows exponentially only with the number of objective functions. For the intractability of determining all extreme efficient solutions in a multi-objective linear program, see Steuer [1994] and Steuer and Piercy [2005]). The proposed approach can be used by companies to redesign their supply chains in order to balance their environmental footprint and life cycle costs of their products. This approach can also be used by governments to evaluate the effectiveness of environmental regulations.

The paper is organized as follows: section 2 briefly reviews the main methodologies used to calculate eco-efficiency. Section 3 presents our methodology, the eco-topology. We focus on the users' interaction in our approach, although the computational results are at least as interesting. Section 4 highlights the comparison between the existing methods and the one we propose. We clearly show the advantages of the latter. In section 5 we illustrate our method, applying it to the reverse logistics network of end-of-life Electrical and Electronic Equipment in Germany. Section 6 presents the conclusions. 


\section{A brief literature review on eco-efficiency}

The idea of a "frontier" for eco-efficiency was first presented by Huppes and Ishikawa [2005]. They also proposed the concept of an eco-frontier with the "optimum" or preferred solution defined by society. Independently, Quariguasi Frota Neto et al. [2007] presented a methodology to assess this frontier and the trade-offs between costs and a single environmental impact factor. This is, as far as we know, the first approach to quantitatively assess the trade-offs between business and the environment, as well as to explore the efficient frontier. The paper of Bloemhof-Ruwaard et al. [2004] advocates the same approach: provide the decision maker with parts or the complete Pareto Efficient Frontier for economic and environmental objectives.

To the best of our knowledge, no other formulation explores the trade-offs between environment and business, as well as the efficient frontier that determines these trade-offs. One stream of research presents a single ratio for eco-efficiency, the single ratio methods. Hellweg et al. [2005] propose a method based on the differences between the differences in associated costs divided by environmental impact indices for different projects. The methodology is only suitable for a discrete number of possible solutions. Scholz and Wiek [2005] propose a similar approach, also based on ratios. They calculate operational eco-efficiency as the improvement of economic utility divided by the improvement in environmental utility. The project under consideration is compared to the business-as-usual alternative. Kuosmanen and Kortelainen [2005] defines eco-efficiency as the ratio of total value added and a damage function, aggregating environmental pressures into a single damage score. Kobayashi et al. [2005] uses Data Envelopment Analysis (DEA) to provide a single measure based on the radial projection of the decision making units (DMUs). These methodologies share two common characteristics. First, they provide a single efficiency measure and implicitly assume the solution with the best ratio is preferred. Second, they are applied to a discrete and small set of possible solutions, mainly to the selection of projects or technologies, whereas most combinatorial optimization problems have many variables and millions of possible solutions. Figure 2 portrays the Single Ratio Methodology Note that the alternative black dots, i.e. representing different projects or technologies, serve as inputs for the model. The frontier 
itself does not map a real solution in this case.

\section{insert figure 2}

\section{insert figure 3}

Krikke et al. [2003] provide three efficiency measures to describe eco-efficiency, i.e. costs, energy use and waste. They use weights to explore the efficient solutions in terms of the environment and business. They rely on the assumption that a weighting process captures the preferred solution for business and the environment. Figure 3 illustrates such procedure, called the Preference Structure Methodology. Note that in this case, the black dots are outputs of the proposed model. Changing the weights in order to explore the efficient frontier may lead to an unbalanced exploration, with some regions being well explored while others are left completely untouched. Unless we use an alternative algorithm to calculate the weight indifferent regions, there is no other theoretical solution for this problem.

\section{insert figure 4}

The two methods do not address the exploration of the efficient frontier or the respective calculation of trade-offs. The assumptions for decision making are that the eco-efficient ratio or the weighting procedure captures the preferred solution(s).

A third methodology is proposed by Quariguasi Frota Neto et al. [2007] using multi-objective programming. The formulation is equivalent to the Preference Structure Method, as it provides the same subset of solutions. For problems with a single environmental impact index, (thus biobjective; cost optimization and environmental optimization), it also provides alternative solutions, based on the convex combination of the extreme efficient points. Furthermore, this approach gives a visual impression of the trade-offs in the bi-objective case. The approach is, however, impractical for problems with thousands of variables, as the number of solutions exponentially increases with the size of the problem. Figure 4 illustrates the results of such approach. 


\section{Exploring eco-efficient solutions, the concept of eco-topology}

Quariguasi Frota Neto et al. [2007] describe the first approach to define the theoretical frontier of Huppes and Ishikawa [2005]. A cradle-to grave approach is used to determine the eco-efficient frontier regarding business and the environment for the design of sustainable logistics networks. In this paper, the diverse phases of a product: raw material extraction, manufacturing, transportation, use and end-of-use alternatives are accounted to determine the optimal solutions. In order to assess the trade-offs and determine the optimum configurations, multi-objective programming is used. A multi-objective programming is denoted by (Steuer and Piercy [2005]):

$$
\begin{gathered}
\max \left\{c^{1} x=z_{1}\right\} \\
\cdots \\
\max \left\{c^{k} x=z_{k}\right\} \\
\text { s.t. }\left\{x \in R^{n} \mid A x \leq b, b \in R^{m}, x \geq 0\right\}
\end{gathered}
$$

where $\mathrm{k}$ is the number of objectives. A point $\hat{x} \in S \subset R^{n}$ is efficient if and only if there is no $x \in S$ such that $c^{i} x \geq c^{i} \hat{x}$ and there is at least one $c^{i} x<c^{i} \hat{x}$. The efficient set or efficient frontier is the set of all efficient solutions.

In our formulation (see section 5 ), $c^{1} x$ represents total profit of a certain configuration, $c^{2} x$ the cumulative energy demand, $c^{3} x$ the respective waste landfilled. The coefficients of the second and third objective function are obtained via Life Cycle Analysis (LCA), a standard technique for evaluating environmental impacts.

Solving the MOLP problem, or finding every extreme efficient solution has two major drawbacks. The first concerns CPU-time. Steuer [1994], Steuer and Piercy [2005] and Papadimitrou and Yannakakis [2001] present computational difficulties in completely exploring the efficient frontier except for small examples. One way to overcome this problem is to interactively explore points on the frontier ${ }^{1}$. The drawback of such a formulation is that complete regions of the frontier may

\footnotetext{
${ }^{1}$ Zeleny [(1974] presents the equivalence between a single objective LP function and a multi-objective one defined in the same feasible polyhedron. Let $\Lambda=\left\{\lambda \mid \lambda_{i} \in E^{k}, \sum_{i=1}^{k} \lambda_{i}=1\right\}, \quad i=1, \ldots, k$ and the LP problem be defined
} 
stay completely unexplored. This approach does not ensure the number of efficient solutions found or the distance between them. The second drawback regards the visualization and interpretation of results. Dividing the environmental impact to three or more subcategories would lead us to a frontier which, besides being very difficult to completely define, is not possible to visualize.

In order to overcome these problems, we propose a new method to explore the efficient frontier, for a MOLP. We call this method eco-topology. The term designates a set of piecewise linear frontiers, named iso-pretium, in which it is possible to change trade-offs between environmental impact classes, e.g. human toxicity and eco-toxicity, while maintaining the same costs. The objective in this formulation is to provide the decision maker with the flexibility to determine his preferred target without the use of interactive processes or weight setting. The algorithm performs in $O\left(\left(\frac{1}{\rho}\right)^{d-1} \times n^{6}\right)$, so computational time grows exponentially with the number of objective functions only.

\section{Algorithm for a 3-objectives case:}

Suppose the decision maker wants to maximize marginal revenue of a reverse logistic network

$\left(z_{1}\right)$, and minimize two environmental impacts $\left(z_{2}\right.$ and $\left.z_{3}\right)$, e.g. cumulative energy demand and landfilled waste. The frontier is constructed as follows:

1. Calculate the $\max \left\{z_{1}\right\}, \min \left\{z_{2}\right\}, \min \left\{z_{3}\right\}$ and check the existence of $z_{1}=0$

2. For $i=1$ to $\frac{1}{\epsilon}$ do

$$
\begin{aligned}
& \hat{z}_{1}=\max \left\{z_{1}\right\} \cdot \epsilon \cdot i \\
& \dot{z}_{2}=\min \left\{z_{2} \mid z_{1}=\hat{z}_{1}\right\} \text { and } \dot{z}_{3}=\min \left\{z_{3} \mid z_{1}=\hat{z}_{1}\right\}, \\
& \ddot{z}_{2}=\min \left\{z_{2} \mid z_{1}=\hat{z}_{1} \wedge z_{3}=\dot{z}_{3}\right\} \\
& \ddot{z}_{3}=\min \left\{z_{3} \mid z_{1}=\hat{z}_{1} \wedge z_{2}=\dot{z}_{2}\right\} \\
& \text { 3. For } j=1 \text { to } \frac{1}{\epsilon} \text { do } \\
& \qquad \hat{z}_{2}=\dot{z}_{2}+\left(\ddot{z}_{2}-\dot{z}_{2}\right) \cdot \epsilon \cdot j \\
& \quad \hat{z}_{3}=\left\{\min z_{3} \mid z_{1}=\hat{z_{1}} \wedge z_{2}=\hat{z_{2}}\right\} \\
& \quad F \leftarrow\left(\hat{z}_{1}, \hat{z}_{2}, \hat{z}_{3}\right)
\end{aligned}
$$

as the $\operatorname{Max}_{x \in X} \sum_{i=1}^{k} \lambda_{i} \cdot f_{i}(x)$ subjected to $x \in X$. Defining $X^{\star}(\lambda)$ as the subset of $x \in X$ that maximizes the function $\lambda f(x)$, we have that $U_{\lambda>0} X^{\star}(\lambda) \in X_{n} \in U_{\lambda \geq 0} X^{\star}(\lambda)$ 
end do

end do

4. Connect lexicographically pairwise the $f \in F$ with the same profit

5. end

where:

$z_{1}$ is the first objective function: marginal revenue of the network

$z_{2}$ is the second objective function: cumulative energy demand,

$z_{3}$ is the third objective function: landfilled waste,

$\epsilon$ is an auxiliary variable: the smaller this variable the higher the number of points on the frontier that are explored, and therefore the better the representation of the frontier.

$F$ is the set of solutions for our formulation

We have to prove that at least one solution exists for each $\hat{z}_{3}=\left\{\min z_{3} \mid z_{1}=\hat{z_{1}} \wedge z_{2}=\hat{z_{2}}\right\}$, and that this solution is Pareto-Optimal. We first proof the following lemmas:

Lemma 1: there is a solution $f \in F$ such that $f=\left(\max \left\{z_{1}\right\} \cdot \epsilon \cdot i, z_{2}^{\circ}, z_{3}^{\circ}\right)$ for every $0<i<\frac{1}{\epsilon}$, where $\dot{z}_{2}, z_{3}$ are values of $z_{2}$ and $z_{3}$

Proof: If there are two solutions $\left(\max \left\{z_{1}\right\}, z_{2}^{\prime}, z_{3}^{\prime}\right)$ and $\left(0, z_{2}^{\prime \prime}, z_{3}^{\prime \prime}\right)$ of a LP, where $z_{2}^{\prime}, z_{2}^{\prime \prime}, z_{3}^{\prime}, z_{3}^{\prime \prime}$ are values of $z_{2}$ and $z_{3}$, respectively, the convex combination of those two solutions is a feasible solution.

Lemma 2: if $\min \left\{z_{2}\right\}$ and $\min \left\{z_{3}\right\}$ exist, all efficient solutions of the original problem with the constraint $z_{1}=\hat{z_{1}}$ are linear combinations of $\left(\hat{z}_{1}, \dot{z}_{2}, 0\right),\left(\hat{z}_{1}, 0, \dot{z}_{3}\right),\left(\hat{z}_{1}, \dot{z}_{2}, \ddot{z}_{3}\right)$ and $\left(\hat{z}_{1}, \ddot{z}_{2}, \dot{z}_{3}\right)$.

Proof: Any solution $\left(\hat{z}_{1}, \check{z}_{2}, \stackrel{\circ}{z}_{3}\right)$ given $\stackrel{\circ}{2}_{2}<\min \left\{z_{2}\right\}$ is unfeasible. The same rationale is valid for $\check{z}_{3}<\min \left\{z_{3}\right\}$. All solutions $\left(\hat{z}_{1}, \stackrel{\circ}{2}_{2}, \stackrel{\circ}{z}_{3}\right)$ given $\stackrel{\check{z}}{2}_{2}>\dot{z}_{2} \wedge \stackrel{\circ}{z}_{3} \geq \ddot{z}_{3}$ and $\stackrel{\circ}{z}_{2} \geq \dot{z}_{2} \wedge \stackrel{\check{z}}{3}_{3}>\ddot{z}_{3}$ are non pareto-optimal. The same rationale is valid for $\check{z}_{3}>\dot{z}_{3} \wedge \check{z}_{2} \geq \ddot{z}_{2}$ and $\check{z}_{3} \geq \dot{z}_{3} \wedge \check{z}_{2}>\ddot{z}_{2}$. The remaining solutions are enclosed in a square with vertexes $\left(\hat{z}_{1}, \dot{z}_{2}, 0\right),\left(\hat{z}_{1}, 0, \dot{z}_{3}\right),\left(\hat{z}_{1}, \dot{z}_{2}, \ddot{z}_{3}\right)$ and $\left(\hat{z}_{1}, \ddot{z}_{2}, \dot{z}_{3}\right)$.

Directly from Lemma 1 , we can always find a solution $f=\left(\max \left\{z_{1}\right\} \cdot \epsilon \cdot i, \stackrel{\circ}{2}_{2}, \check{z}_{3}\right)$. If $\min \left\{z_{2}\right\}$ and 
$\min \left\{z_{3}\right\}$ are bounded, there is a solution for $\dot{z}_{2}$ and $\dot{z}_{3}$. Using Lemma 2 , and the fact that all extreme efficient solutions are connected $\left(\left(\hat{z}_{1}, \dot{z}_{2}, \ddot{z}_{3}\right)\right.$ and $\left(\hat{z}_{1}, \ddot{z}_{2}, \dot{z}_{3}\right)$ are also Pareto-optimal), there is a path from $\dot{z}_{2}$ to $\dot{z}_{3}$ that can be expressed as the linear combination of $\left(\hat{z}_{1}, \dot{z}_{2}, 0\right),\left(\hat{z}_{1}, 0, \dot{z}_{3}\right)$, $\left(\hat{z}_{1}, \dot{z}_{2}, \ddot{z}_{3}\right)$ and $\left(\hat{z}_{1}, \ddot{z}_{2}, \dot{z}_{3}\right)$. Therefore for any $\hat{z}_{2}=\dot{z}_{2}+\left(\ddot{z}_{2}-\dot{z}_{2}\right) \cdot \epsilon \cdot j$ there will be one and only one Pareto-optimal point (not necessarily a vertex) $\left(\hat{z_{1}}, \hat{z_{2}}, z_{3}\right)$. Once $\hat{z_{1}}$ and $\hat{z_{2}}$ are constants, this point is $\hat{z}_{3}=\left\{\min z_{3} \mid z_{1}=\hat{z_{1}} \wedge z_{2}=\hat{z_{2}}\right\}$

The figure 5 illustrates the algorithm.

\section{insert figure 5}

The solutions F are not necessarily Pareto-optimal with respect to the original MOLP, due the constraint $z_{1}=\hat{z_{1}}$, but they are Pareto-optimal for the original problem plus constraint $z_{1}=\hat{z_{1}}$. The model could also incorporate another step to test the solutions in F for Pareto optimality. In our case study (section 5) we test them "a posteriori", and differentiate in the graphical representation the Pareto-optimal from the non Pareto-optimal. The objective is to lock out non Pareto-optimal solutions, allowing the decision maker to identify them, as well as allowing a visual representation of the parts of the frontier in which win-win situations are still possible.

\section{Comparison between Eco-topology and the existing meth- ods}

We compare the eco-topology methodology with the three methodologies presented in section 2: 1) the single ratio methods, 2) the Preference Structure methods based on weighting and 3) the multi-objective methods based on the complete exploration of the extreme efficient vertices. We also draw parallels between the different methodologies.

The single ratio methodology proposes a single efficiency measure to select one solution out of a set of solutions, according to the highest $\frac{\text { Economic Value }}{\text { Environmental Pressure }}$ ratio. The main drawbacks of such formulation are:

- it is not possible to differentiate between different environmental impacts or to add new 
variables to the model, such as social aspects or performance levels.

- it does not give any information on the theoretical trade-offs between the dimensions of analysis (in our case business and planet).

- The decision maker has no flexibility to choose targets according to his most preferred solution. A high rate could, for example, be possible only via a cheap and environmentally unfriendly process; or alternatively, an extremely environmental friendly process with extremely high costs. Both could be undesirable, if not unrealistic.

In mathematical terms, the ratio procedure is nothing but a DEA model with two variables and constant returns of scale. It can only be applied to a discrete set of alternatives. The eco-topology approach allows the decision maker to freely decide on the best trade-offs or location on the optimal frontier. It also allows an increment on the number of objectives, allowing discrimination between the different environmental pressure classes and the insertion of new variables, such as performance levels. The trade-offs between these variables can be determined and easily visualized via the iso-pretium curves. In the case of discrete solutions, the model should be adjusted for DEA formulations.

The Preference Structure methodology, partial exploration, is equivalent to an interactive version of the eco-curves. It is a heuristic approach as it provides a subset of solutions. First, it only explores the efficient vertices, not the corresponding hyperplanes. Second, it is not possible to ensure that all extreme points are explored. The number of alternatives is then diminished. The weighting procedure is another drawback, since the weights may not correspond to their implicit importance. A weight of $70 \%$ for the environment does not necessarily mean a solution which takes the environment for $70 \%$ into account, contrary to common belief. Furthermore, it is also not possible to determine any trade-off between different dimensions.

The Multi-objective methodology is the one most closely related to the concept of eco-topology. Here, the objective is to completely explore the set of all efficient extreme solutions. This formulation gives the DM a set (in general with exponential size) of efficient solutions. In this case 
flexibility is given to the decision maker to decide between a given number of alternatives. There is one serious drawback: it cannot be applied to big instances. An increase in the number of variables, therefore, may turn the problem unsolvable from a CPU-time perspective. The ecotopology is a polynomial time scheme, and its complexity grows exponentially with the number of dimensions in the problem only. The number of variables and constraints do grow polynomially. The main drawback of the proposed method is the computational complexity as compared to the Preference Structure methodology. So far we have not mentioned the articulated approach. In the articulated methods the Decision Maker interacts with the model until he finds a satisfying solution. An example of such approach is the Pareto Race, or STEM , which promotes a "walk" on the facets of the frontier (Korhonen and Syrjanen [2003]). The Pareto Race enables a decision maker to freely search any part of the efficient frontier by controlling the speed and direction of motion. The values of the objective functions are presented during the Race as bar graphs on a display. For discrete problems, multi-attribute methods may also be used. We have found no literature on articulated methods for Eco-efficiency analysis, but it seems to be another fruitful area of research.

Table 1 describes the different types of methodologies, their applicability, main advantages and limitations.

\section{insert table 1}

\section{The German Waste Electrical and Electronic (WEEE) case}

In the following, the algorithm described in Section 3 is applied to a real-world case study regarding the implementation of the Directive for recycling waste electrical and electronic equipment (WEEE-directive). It is the aim of this part of the paper to show the applicability of the ecotopology method, and to demonstrate how the method helps in the decision making process by visualization of efficient alternatives and calculation of trade-offs. 


\subsection{Description of the problem}

According to the European Commission, the amount of waste electrical and electronic equipment (WEEE) is growing rapidly. Since WEEE contains hazardous as well as valuable substances, and must be treated properly, the directive of the European Parliament and the European Council on waste electrical and electronic equipment (WEEE-directive [2003]) is aiming at prevention, re-use, material recycling and energy recovery of WEEE. The overall goals of the directive are to reduce the amount of waste that is disposed of, and to improve the environmental performance of all processes along the life cycle of electrical and electronic equipment. As result of the directive, recycling systems have to be implemented in countries with a poorly developed recycling infrastructure like in Spain or the East European countries. However, in other countries like Germany or The Netherlands, there already exists an adequate infrastructure, and the main question is how to allocate WEEE using the given infrastructure. In the following, we will focus on the latter case, and show how to support decision makers like politicians, recyclers, and manufacturers of electronic products by calculating efficient solutions and trade-offs for optimal operation of a given recycling system. In order to determine the efficient frontier aiming at economic as well as ecological objectives, we apply the algorithm presented in chapter 3. The algorithm is applied based on a model describing the all material flows and processes possible within the given infrastructure, which is presented in the following. As material flows and processes within the reverse logistics network system, various tasks like acquisition and collection, transportation, sorting, disassembly, re-use, recycling and recovery of products, as well as storage and selling of material fractions are conducted as is presented in figure 6. As can be seen, discarded electronic products are first transported from collection points to treatment companies. There, products are disassembled, i.e. harmful substances are removed, and valuable materials as well as re-usable spare parts are gained. Different disassembly depths as well as mechanical processing activities can be applied. After treatment, tradable material fractions of defined quality are sold or are disposed of. Metal fractions are supplied to metal or steel works for material recycling, plastics are either utilized for energy recovery or land-filled. 


\section{insert figure 6}

According to the WEEE-directive, all electronic products coming back from the end-user have to be treated properly. Thus, this WEEE amount is given as fixed input to be treated by the system. However, there are many decisions that is to be decided on with regard to how to treat these products. Decisions to be made when implementing the WEEE-directive within an existing infrastructure are:

- masses of product type $i$ transported from source $q$ to treatment company $u\left(y_{i q u}^{Q}\right)$, and between treatment companies $\left(y_{\text {iuu }}^{Q}\right)$

- number of treatment activities $j$ to be applied, i.e. how often is a certain disassembly depth or mechanical processing activity chosen $\left(x_{j u}\right)$

- masses of material fraction $i$ generated depending on the treatment activities, and recovery or disposal site $r$, these fractions are transported to $y_{\text {iur }}^{R}$ depending on current market prices.

Based on all material flows possible within a given infrastructure, the target is to select the best allocation out of all possibilities. To be able to do so, objectives are to be known. Often, companies as well as politicians are aiming at the most efficient economic solution. In such a case, the contribution margin is to be maximized as result of all product and recycling revenues minus variable disassembly, transportation, and sorting costs (see (1)). For this single objective problem, the model and results are described in Walther and Spengler [2005].

However, if the environmental aims of the WEEE-directive are to be taken into account, more than one objective function is to be taken into account. The WEEE-directive is aiming at two different environmental aims: reduction of ecological impacts on the one hand, and resource protection respective waste minimization on the other hand.

In the following, the Cumulative Energy Demand (CED) is chosen as aggregated screening indicator for ecological impacts. CED represents the primary energy used over the life cycle of a 
good or for a certain process (VDI 4600, 1997), and has shown good correlations to different ecological impact categories, e.g. global warming potential (Huijbregts et al. [2005]). For our example, CED is calculated for transportation processes by multiplying total masses to be transported $\left(y_{i q u}^{Q}, y_{i u r}^{R}, y_{i u u^{\prime}}^{U}\right)$ with distance and mode specific CED-coefficients for transportation processes $\left(c e d_{i q u}^{Q}, c e d_{i u u^{\prime}}^{U}, c e d_{i u r}^{R}\right)$. For treatment processes, the number of activities $\left(x_{j u}\right)$ is multiplied with activity specific CED-coefficients (e.g. energy used per disassembly activity). For calculation of the CED-coefficients, we used on the one hand generic data of data bases like SimaPro (CED for transportation processes, energy production based on a national energy mix), and on the other hand specific data determined by empirical analyses (e.g. specific energy demand of a shredder). The equation for calculation of CED is given in (2). Another goal of the WEEE-directive is to minimize waste. Thus, the total amount of waste (i.e. materials that are sent to landfills and incinerators) is to be minimized. This amount is calculated as total input masses entering the treatment system $\left(y_{i u q}^{Q}\right)$ minus total output masses that are recycled. Recycled masses are calculated multiplying total output masses with recycling coefficients. These recycling coefficients have values between 0 and 1 , and determine the part of a material fraction that is assumed to be recycled. Coefficients are determined at national level, and depend on quality of the material fraction $i$ as well as on the facility type $r$ this fraction is sent to (kopol, 2004). The equation for waste minimization is given in (3).

$$
\begin{gathered}
\max \sum_{u=1}^{U}\left(\sum_{i=1}^{I}\left(\sum_{q=1}^{Q}\left(e_{i}^{A}-c_{i q u}^{Q}\right) \times y_{i u q}^{Q}+\sum_{u=1, u \neq u^{\prime}}^{U}\left(-c_{i u u^{\prime}}^{U}\right) \times y_{i u u^{\prime}}^{U}+\sum_{r=1}^{R}\left(e_{i r}^{V}-c_{i u r}^{R}\right) \times y_{i u r}^{R}\right)-\sum_{j=1}^{J} x_{j u} \times c_{j u}^{Z}\right) \\
\min \sum_{u=1}^{U}\left(\sum_{i=1}^{I}\left(\sum_{q=1}^{Q} c e d_{i q u}^{Q} \times y_{i u q}^{Q}+\sum_{u=1, u \neq u^{\prime}}^{U} c e d_{i u u^{\prime}}^{U} \times y_{i u u^{\prime}}^{U}+\sum_{r=1}^{R} c e d_{i u r}^{R} \times y_{i u r}^{R}\right)+\sum_{j=1}^{J} x_{j u} \times c e d_{j u}^{Z}\right) \\
\min \sum_{u=1}^{U}\left(\sum_{i=1}^{I}\left(\sum_{q=1}^{Q} y_{i u q}^{Q}-\sum_{r=1}^{R} y_{i u r}^{R} \times r e c_{i r}\right)\right)
\end{gathered}
$$


These objectives are to be followed taking certain restrictions of the recycling system into account. First, material balances are set up for every single disassembly company of the network. The output of a treatment company $\left(y_{i u}^{D}\right)$ is given by the net result of all inputs of appliances from sources outside the network $\left(y_{i u q}^{Q}\right)$, the input of appliances and material fractions from other treatment companies $\left(y_{i u u^{\prime}}\right)$, and the transformation of masses related to treatment. Latter is expressed as the number of executions of a treatment activity $\left(x_{j u}\right)$ multiplied with an input-output-coefficient $\left(v_{i j}\right)$ specifying the input-output-relationships of products and material fractions $i$ of this activity $j$.

$$
\left(\sum_{j} x_{j u} \times v_{i j}\right)+\sum_{q=1}^{Q} y_{i u q}^{Q}+\sum_{u=1, u \neq u^{\prime}}^{U} y_{i u u^{\prime}}^{U}=y_{i u}^{D} \quad i=1, \ldots, I ; u=1, \ldots, U
$$

According to $(5)$ the output of a treatment company $\left(y_{i u}^{D}\right)$ is either delivered to recovery companies or disposal sites $\left(y_{\text {iur }}^{R}\right)$ or to other (specialized) treatment companies $\left(y_{i u u^{\prime}}\right)$.

$$
y_{i u}^{D}=\sum_{u=1, u \neq u^{\prime}}^{U} y_{i u u^{\prime}}^{U}+\sum_{r=1}^{R} y_{i u r}^{R}, \quad i=1, \ldots, I ; u=1, \ldots, U
$$

In addition to these material balances, different external and internal restrictions exist. All products available at sources must be accepted and properly treated (6). Additionally, restrictions exist regarding treatment capacities at companies (7), which are described in maximal costs the company is able to spent because of capacity restrictions. For example, the number of employees (or working stations) available at one company times the costs for one worker for one month determines the capacity (given in costs) that is available for manual recycling. This description is chosen, since capacity depends on durability of activities performed. Additionally, capacities at recovery and disposal sites are to be regarded (8).

$$
\begin{gathered}
\sum_{u=1}^{U} y_{i u q}^{Q}=y_{i q}^{Q M A X}, \quad i=1, \ldots, I ; q=1, \ldots, Q \\
\sum_{j=1}^{J} c_{j u}^{z} \times x_{j u} \leq c_{u}^{Z M A X} \quad u=1, \ldots, U
\end{gathered}
$$




$$
\sum_{u=1}^{U} y_{i u r}^{R} \leq y_{i r}^{R M A X} \quad i=1, \ldots, I \quad r=1, \ldots, R
$$

Additionally, the non-negativity constraints are set (9)

$$
y_{i u q}^{Q}, y_{i u u^{\prime}}^{U}, x_{j u}, y_{i u r}^{R}, y_{i u}^{D} \geq 0
$$

\subsection{Application of the algorithm}

In the following, the algorithm of Section 3 is applied to the WEEE case study. With regard to the given objectives, it is the overall aim to calculate the optimal allocation and treatment processes within a given infrastructure with regard to the requirements of the WEEE-directive following economic as well as ecological goals. Since we want to calculate efficient allocations based on decisions about masses $(\mathrm{kg})$, the solution space is continuous. As stated in section 3 , it is not our intention to determine one preferred solution (as would be done by a-priory weighting of the different goals of the decision makers), but to visualize all efficient solutions and trade-offs between the different goals. Since we have three objectives, it is a three-dimensional efficient frontier, but we want to present it as two-dimensional trade-offs on isopretium curves (thus, keeping the contribution margin constant for every curve). Based on the visualization of the efficient frontier and the trade-offs, a discussion process can start which of the solutions to chose (subjective part). We do not want to replace this discussion, but rather help in the decision making process by an presentation and visualization of all alternatives and trade-offs to the decision makers (objective part). The application of the algorithm is done for a sample region, the federal state of Lower Saxony in Germany. Actors, activities and material flows were determined within an empirical study. As a result of this analysis, 47 public waste collection points, 46 disassembly and mechanical processing companies, and 56 recycling and disposal sites with their location, specialization as

well as treatment capacities were determined. Since electronic products are very heterogeneous, seven reference products resembling the average of several products were defined according to product similarities based on empirical data. Four to six disassembly depths and mechanical pro- 
cessing activities with corresponding quality and quantity of materials fractions were determined for every reference product. The resulting optimization problem consists of approximately 71.000 linear variables and 11.000 conditions. For the one objective case, the problem can be solved using common solution procedures for linear optimization problems in few seconds.

When applying the algorithm the profit (objective 1) is first maximizing ignoring all other objectives. In the WEEE case, the maximum attainable profit is $1.1 \mathrm{Mio.} € / \mathrm{y}$ if CED and waste are not taken into account. This solution would be the result of a single (economic) objective optimization model, and would be chosen by a decision maker following purely economic targets. A certain number of isopretium curves is then calculated by multiplying the maximum profit with coefficients $\epsilon \cdot i$ for all $i=1, \ldots, \frac{1}{\epsilon}$. Thus, each isopretium is representing a certain fraction of the maximum profit. In the WEEE case, 10 isopretium curves are calculated $(\epsilon=0.1)$, which means that the lowest profit isopretium curve $(110,000 € / y)$ is representing $1 / 10$ th of maximum profit. For each of these ten fractions of the maximum profit, CED (objective 2) as well as waste (objective 3) are minimized separately. Doing so, the solution space is limited since unfeasible solutions (i.e. all results representing less then the minimum attainable CED and waste) can be eliminated for each isopretium curve. In the WEEE case for example, it is not possible to reach less than 5,700 GJ/y CED and 2,380 t/y of waste if a profit of $220,000 € / \mathrm{y}$ is at least aimed at. Thus, if at least 220,000 e/y must be reached, the given input amount of WEEE that is collected can not be processed generating less than 5,700 GJ/y CED and 2,380 t/y waste. Keeping the profit as well as the minimal attainable CED unaltered, the minimal waste is now calculated. For a profit of $220,000 € / \mathrm{y}$ and $5,700 \mathrm{GJ} / \mathrm{y}$ of CED this results in $5,830 \mathrm{t} / \mathrm{y}$ of waste . The same is done keeping the objective value of the profit as well as the minimal waste unchanged, which is for the example a profit of $220,000 € / \mathrm{y}$ and waste of $2,380 \mathrm{t} / \mathrm{y}$ resulting in $8,940 \mathrm{GJ} / \mathrm{y}$ of CED. Note that there is a trade-off between CED and waste minimization in the WEEE case. Therefore, the minimization of CED and the minimization of waste each lead to maximum values for the other objective for a given profit. Applying these calculations, the solution space is bounded, and the 
starting and ending points of the isopretium curve are now known. Thus, the curve connecting these two points can be calculated. This is done by slowly raising the CED by a certain fraction $\epsilon \cdot i$ for all $i=1, \ldots, \frac{1}{\epsilon}$, and each time calculating the minimized waste for this combination of maximized profit/minimized CED until the maximum CED (and thus in the WEEE case the minimum waste) is reached for this isopretium. The results are stored, and the algorithm is repeated by slowly raising the profit objective by $110,000 € / y(\epsilon \cdot$ maximum profit $)$ until the maximum profit is reached.Figure 7 illustrate the search for a $220,000 € / y$ isopretium.

\section{insert figure 7}

\subsection{Results}

Results are shown within figure 7. In this figure, direct trade-offs between CED and waste are given on every iso-pretium curve. However, trade-offs between profit and CED (respectively profit and waste) can also be deduced when changing from one iso-pretium curve to another if the other ecological impact is kept constant. For our case study, the solution space is continuous. Thus, to every point on the iso-pretium curve belongs to one or several solutions with a certain characteristic of decision variables. For instance, to a certain combination of CED, waste and profit belongs a certain amount of products that is delivered from collection point q to treatment company $u$, where a certain number of disassembly activities is applied and as result certain material fractions i are generated that are then sent to recycling facility r. Since there are millions of possible (and even efficient) solutions, we will not focus on the solution itself, but rather on the efficient frontier and the trade-offs. A more sophisticated analysis of different solutions is given in Walther and Spengler [2005].

The results of the iso-pretium curves are represented in figure 8. The curve ending on the right of the others represents the iso-pretium for a profit of $90 \%$ of the maximum profit, or $990,000 € / y$. The one ending on the left of all other represents the iso-curve for a profit of $20 \%$ the maximum profit, $220,000 € / y$. The curves in between represent, respectively $30 \%, 40 \%, 50 \%, 60 \%, 70 \%$ and $80 \%$ of the maximum profit. The maximum profit $(100 \%)$ has a single point $(5,488 \mathrm{t} / \mathrm{y}$ and 
$5,892 \mathrm{GJ} / \mathrm{y})$.

\section{insert figure 8}

Looking at the iso-pretium curves, it can be observed that decreasing landfill is only possible via increasing in the cumulative energy demand (CED). Our results show that there is very little room for trade-off between the two environmental indicators, and the profit of the reverse supply chain. In other words, selecting less profitable supply chains do not render improvements in both environmental indicators. The reason seems to be the energy spent with transportation: the electrical and electronic equipment being diverted from landfill to other end-of-use alternatives (i.e. recycling) results in higher transportation efforts. Two facts help to explain this phenomena. First, the fact that landfills are usually more abundant than recycling facilities, and therefore, in average close to the consumer centers helps to explain the inverse correlation of transportation (and therefore CED) and amount of end-of-life electronic ending at landfills. As land-filled waste decreases, therefore, CED increases. Second, the level of reduction on land-filling due to other end-of-life activities (i.e. recycling) are different for the different end-of-life facilities. In order to get a higher recycling percentage the equipment may have to travel longer distances.

Another interesting result is that the reduction in waste due to an unitary increase in CED rapidly deteriorates with the increase in CED. This particular result holds for all iso-pretium curves. At a 220,000 Mio $€ / y$ profit, and a CED of 5,700 GJ/y, an increase of one MJ reduces $6.11 \mathrm{~kg}$ of waste landfilled. For the same unitary reduction, and a CED of $8,770 \mathrm{GJ} / \mathrm{y}$, the reduction is only $0.08 \mathrm{~kg}$. For this particular iso-pretium curve, the "shadow price" of waste per unit in kilograms per CED in GJ changes $7600 \%$ from the highest to the lowest CED levels. The results are robust for the other iso-pretium curves. For the iso-pretium curve of $330,000 € / y, 440,000 € / y, 550,000$ $€ / y, 660,000 € / y, 770,000 € / y, 880,000 € / y$ we have changes in the "shadow prices" of waste (in $\mathrm{kg}$ ) per CED (in MJ), respectively, from $6.23 \mathrm{~kg} / M J$ to $0.04 \mathrm{~kg} / \mathrm{MJ}, 6.35 \mathrm{~kg} / \mathrm{MJ}$ to $0.04 \mathrm{~kg} / \mathrm{MJ}$, $6.49 \mathrm{~kg} / \mathrm{MJ}$ to $0.04 \mathrm{~kg} / \mathrm{MJ}, 6.67 \mathrm{~kg} / \mathrm{MJ}$ to $0.03 \mathrm{~kg} / \mathrm{MJ}, 7.71 \mathrm{~kg} / \mathrm{MJ}$ to $0.16 \mathrm{~kg} / \mathrm{MJ}, 8.25 \mathrm{~kg} / \mathrm{MJ}$ to $0.06 \mathrm{~kg} / \mathrm{MJ}$.

Also worth noticing is the fact that the reduction in the amount of waste going to landfill due to 
decrease in the profitability of the supply chain is not much affected by the level of profitability or CED. For a cost of $660,000 € / y$ and a CED of $7,820 \mathrm{GJ} / \mathrm{y}$, a reduction in landfilling costs is approximately $1 € / \mathrm{kg}$, maintaining the level of CED. In the same iso-pretium, and a CED of $7,180 G J / y$, the reduction in landfilling costs is approximately $1.3 € / \mathrm{kg}$. The result is robust for all iso-pretiums. For a profit of $330,000 € / y$ and a CED of $8,620 \mathrm{GJ} / \mathrm{y}$ the reduction in landfilling is $1.4 € / \mathrm{kg}$. The cost for reduction in landfill is $2 € / \mathrm{kg}$ for a $8,620 \mathrm{GJ} / \mathrm{y} \mathrm{CED}$. The values are quite high compared to normal take-back prices. A $12 \mathrm{~kg}$ computer would cost between $12 €$ to $20 €$. Looking at the results for shadow-price of CED, one can note that they rapidly increase with the increase in profitability. From iso-pretium with profit of $330,000 € / y$ to iso-pretium with profit of $220,000 € / \mathrm{y}$ at a $8,620 \mathrm{GJ} / \mathrm{y} \mathrm{CED}$, the unitary reduction costs $0.12 € / \mathrm{MJ}$. The same reduction from iso-pretium with profit of $880,000 € / y$ to $770,000 € / y$ results in unitary cost of $0.46 € /$ MJ for a $6,710 \mathrm{GJ} / \mathrm{y}$ CED. Both results seem quite high: buying the comparative amount of carbon credit would cost $0.003 € / \mathrm{MJ}$ (Carbonfund-Organization [2006]).

Comparing these different iso-pretium curves, one can infer that minimizing land-filled waste can only be achieved if a low profit is taken into account, or if transportation (and therefore CED) is increased. This is an interesting result with regard to the European WEEE-directive, which is aimed at minimizing the amount of EEE waste that is sent to landfill,

If the aforementioned transparency of trade-offs could be provided before legislative procedures start, political decision-makers could gain a deeper insight into the impacts of legal measures. Non-intuitive results (e.g. increase in CED with a lower amount of land-filled waste ) could be anticipated. Additionally, the level of effort necessary to fulfill new legal measures (e.g. high recycling costs necessary for minimizing the land-filled waste or high shadow-prices for CED) could be shifted to other processes or other product life-cycle phases, where higher environmental gains could be achieved with the same monetary efforts.

The proposed model provides decision makers with an easy tool for selecting the preferred solution regarding business and environmental indicators. For the German WEEE case, the decision maker can visually inspect the solutions and point his preferred one, and the model will indicate a network 
with decisions regarding end-of-life destination (i.e. recycling, landfill) and respective allocations. Furthermore, the model provides the trade-offs between waste ending in landfills and CED for supply chains with same costs. It is also possible to calculate the costs for reducing CED and landilled waste, for different levels of the environmental indicators. Those results are not available for the aforementioned models based on single efficiency measures or methods based on linear programming weighting.

\section{Conclusions and Outlook}

In this paper we develop a methodology to explore Pareto optimal solutions for business and the environment. Our methodology allows decisions makers to assess their preferred solution via one of the decision makers' most effective cognitive capabilities, visual inspection. Furthermore, the resulting iso-pretium curves permit the assessment of the trade-offs among the environmental impact indicators and the profit of a given logistics network. In other words, the methodology helps to answer questions: (i) How to determine the preferred solution(s) balancing environment and business? and (ii) what are the trade-offs between the aforementioned two dimensions? The emerging streams of research on eco-efficiency, namely, 1) methods based on single efficiency index, 2)methods based on weighting or 3) multi-objective methods based on the complete exploration of the extreme efficient vertices, do not provide satisfying solutions for the proposed questions. Furthermore, for the multi-objective methods, CPU-time grows fast with the size of the problem. In this paper we focus on the exploration of the eco-topology concept for the MOLP (Multi Objective Linear Programming Model). Quite some problems regarding eco-efficiency can be modeled as such. Applications are allocation and end-of-use decisions Bloemhof-Ruwaard et al. [1996] and Walther and Spengler [2005], and disassembly decisions (see Lambert [1999] and Lambert [2003]). The model can also be extended to combinatorial problems, but some remarks are worth to be made. First, problems that cannot be $\epsilon$-approximated cannot be modeled: if you can't find a single approximation for the problems, you can't find a set(Papadimitrou and Yannakakis [2001]). It eliminates, therefore, the whole class of APX-hard problems. An $\epsilon$-approximation is not possible 
for models including decisions regarding the location of facilities such as in Fleischmann et al. [2000] and Krikke et al. [2003]. An alternative approach for such problems is to determine the solution and then compare this solution with a relaxed solvable form. For more on $\epsilon$-approximation of combinatorial multi-objective problems see Papadimitrou and Yannakakis [2001]. Second, in combinatorial problems, it is clear that something like a frontier does not exist. In case we define such a frontier as in DEA, notice that convexity will be lost due to the unsupported solutions. Identifying future research in this area is simultaneously an easy and a hard task. Easy because the methodologies available for multi-criteria Decision Making (MCDM) and MOP have yet barely been applied for these specific problems. Methodologies such as ELECTRE for discrete problems, and Pareto-Race and STEM for continuous problems have not yet been explored for the assessment of preferred solutions for business and the environment. Hard because it is not clear which existing methods will bring better results. Further research on the most relevant phases for improving eco-efficiency (i.e. in a logistics network, transportation, manufacturing, procurement, end-of-use) has to be carried out, as well as on the computational difficulties of the models. 


\section{$7 \quad$ Table and Figures}

Indices and Sets:

$i \quad$ products and materials $(i \in I)$

$j \quad$ recycling operations $(j \in J)$

$u \quad$ recycling companies $(u \in U)$

$r \quad$ recovery/disposal facilities $(r \in R)$

$q \quad$ collection points $(q \in Q)$

Decision variables:

$y_{i q u}^{Q} \quad$ mass of discarded product type $i$ delivered from collection point $q$ to recycling company $u$

$y_{i u r}^{R} \quad$ mass of material type $i$ delivered from recycling company $u$ to recovery/disposal facility $r$

$x_{j u} \quad$ number of executions of recycling operation $j$ in recycling company $u$

$y_{i u u^{\prime}}^{U} \quad$ mass of discarded product type $i$ delivered from recycling company $u$ to recycling company $u^{\prime}$

Parameters:

$v_{i j} \quad$ recycling operation coefficient representing input(-)/output(+) masses of product/material type $i$ consumed/caused by one execution of recycling operation $j$

$e_{i}^{A} \quad$ acceptance fees, the network gets for treating one kilogramme of product type $i$ 


\footnotetext{
$c_{i q u}^{Q} \quad$ costs for transportation of one kilogramme of material type $i$ from collection point $q$ to recycling company $u$

$c_{i u u^{\prime}}^{U} \quad$ costs for transportation of one kilogramme of material type $i$ from recycling company $u$ to recycling company $u^{\prime}$

$c e d_{i q u}^{Q} \quad$ CED for transportation of one kilogramme of material type $i$ from collection point $q$ to recycling company $u$ $c e d_{i u r}^{R} \quad$ CED for transportation of one kilogramme of material type $i$ from recycling company $u$ to recovery/disposal facility $r$

ced $d_{\text {iuu }}^{U} \quad$ CED for transportation of one kilogramme of material type $i$ from recycling company $u$ to recycling company $u^{\prime}$

$\operatorname{ced}_{j u}^{Z} \quad$ CED for recycling activity $j$ at recycling company $u$ $e_{i r}^{V} \quad$ sales revenue(+)/disposal cost(-) for delivery of one kilogramme of material type $i$ to recovery/disposal facility $r$ $c_{i u r}^{R} \quad$ costs for transportation of one kilogramme of material type $i$ from recycling company $u$ to recovery/disposal facility $r$ $c_{j u}^{Z} \quad$ costs for the application of one recycling operation $j$ in recycling company $u$

rec $_{i r} \quad$ fraction of material type $i$ that was sent to recovery facility $r$ approved to be recycled $y_{i q}^{Q M A X}$ mass of product type $i$ that has to be collected at source $q$ $y_{i r}^{R M A X}$ capacity available at recovery/disposal facility $r$ $C_{u}^{Z M A X}$ capacity available at recycling company u
} 


\begin{tabular}{|c|c|c|c|c|c|c|}
\hline ID & Family & papers & trade-off? & Flex.? & C. Class? & Visual Trade-off? \\
\hline 1 & Single Ratio & $\begin{array}{c}\text { Kuosmanen and Kortelainen [2005] } \\
\text { Hellweg et al. [2005] } \\
\text { Scholz and Wiek [2005] } \\
\text { Kobayashi et al. [2005] }\end{array}$ & NO & NO & - & NO \\
\hline 2 & weighting LP & $\begin{array}{c}\text { Bloemhof-Ruwaard et al. [2004] } \\
\text { Krikke et al. [2003] }\end{array}$ & NO & YES & P & NO \\
\hline 3 & Multi-objective & Quariguasi Frota Neto et al. [2007] & YES/NO & YES & NP-hard & YES/NO \\
\hline 4 & Eco-Topology & - & $Y E S$ & YES & FPTAS & YES \\
\hline
\end{tabular}

table 1: Main streams of research on eco-efficiency

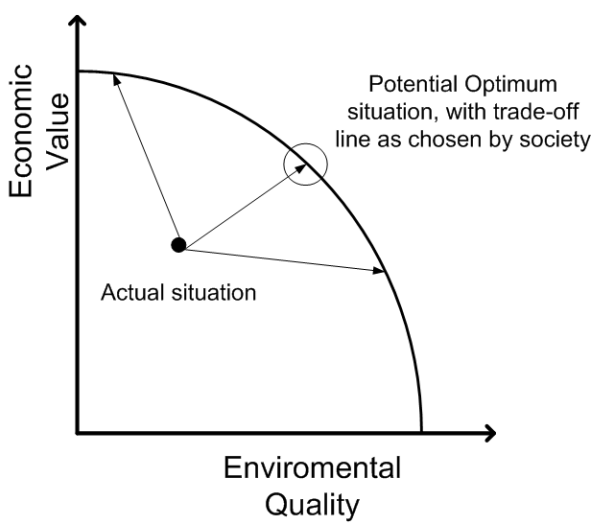

Figure 1: Eco-efficiency in society: Actual technologies and production possibility envelope. Adapted from Huppes and Ishikawa [2005]. 


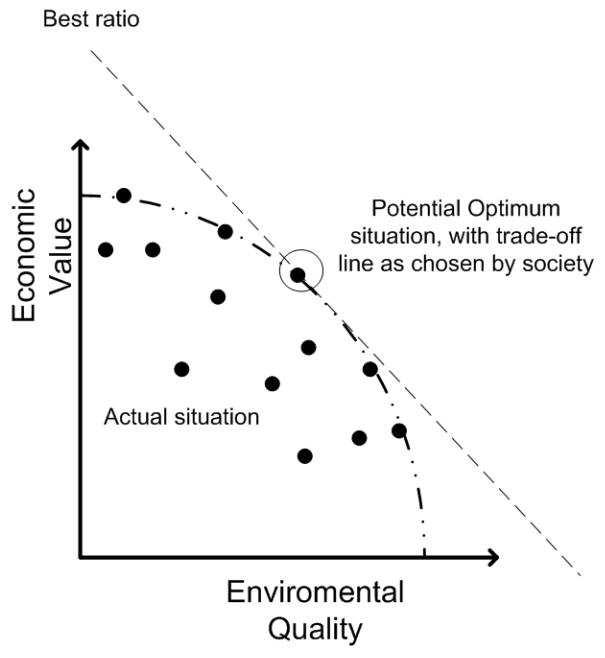

Figure 2: The Single Ratio method

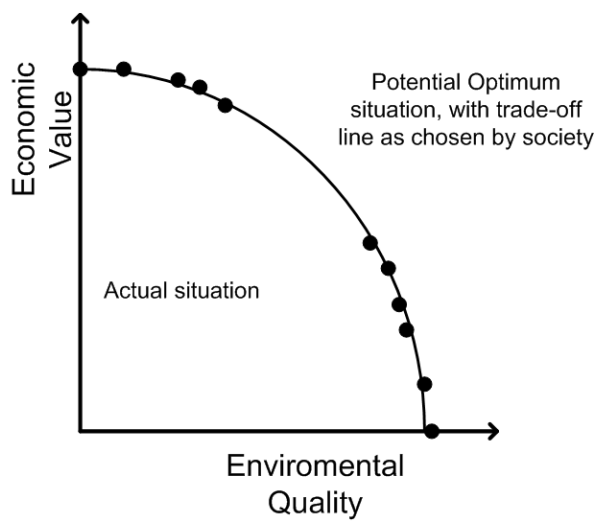

Figure 3: The Weighting method (also called Preference Structure Method)

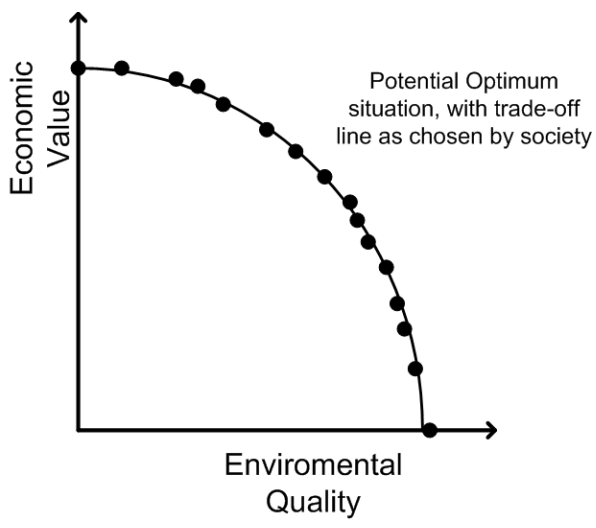

Figure 4: The Multi-Objective method 


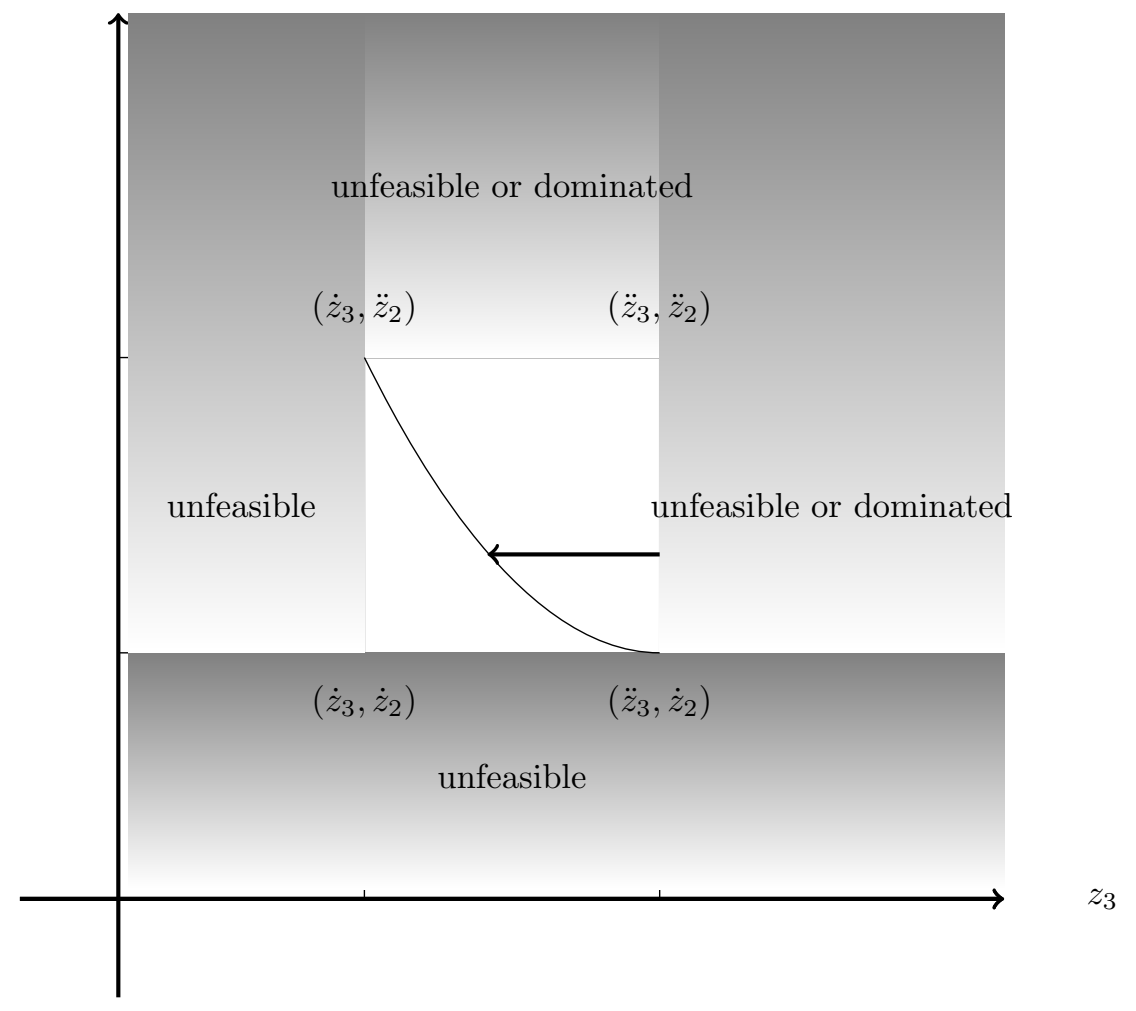

Figure 5: The proposed search for equally dispersed pareto-efficient solutions 


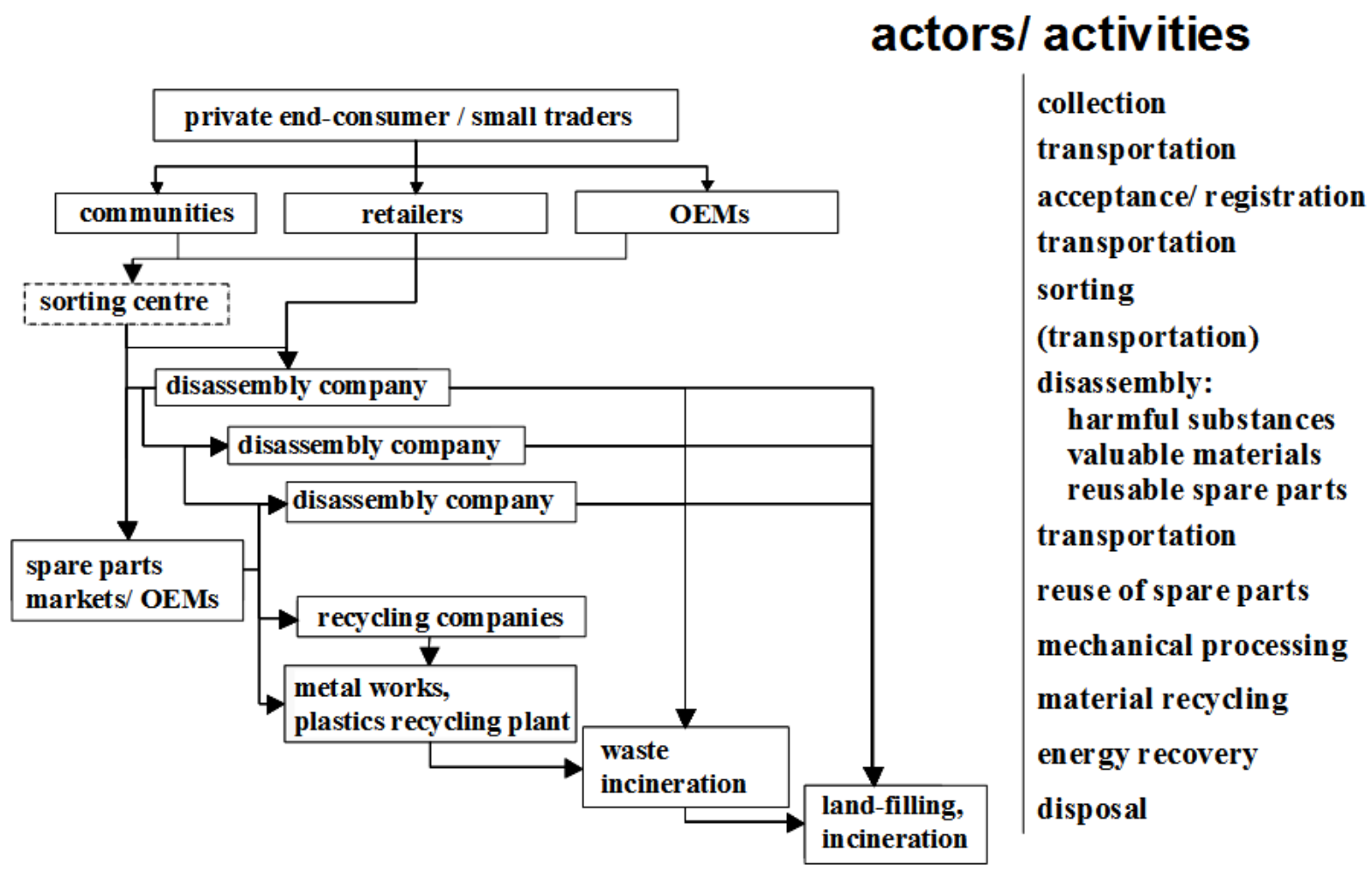

Figure 6: Actors and activities within the field of WEEE treatment 


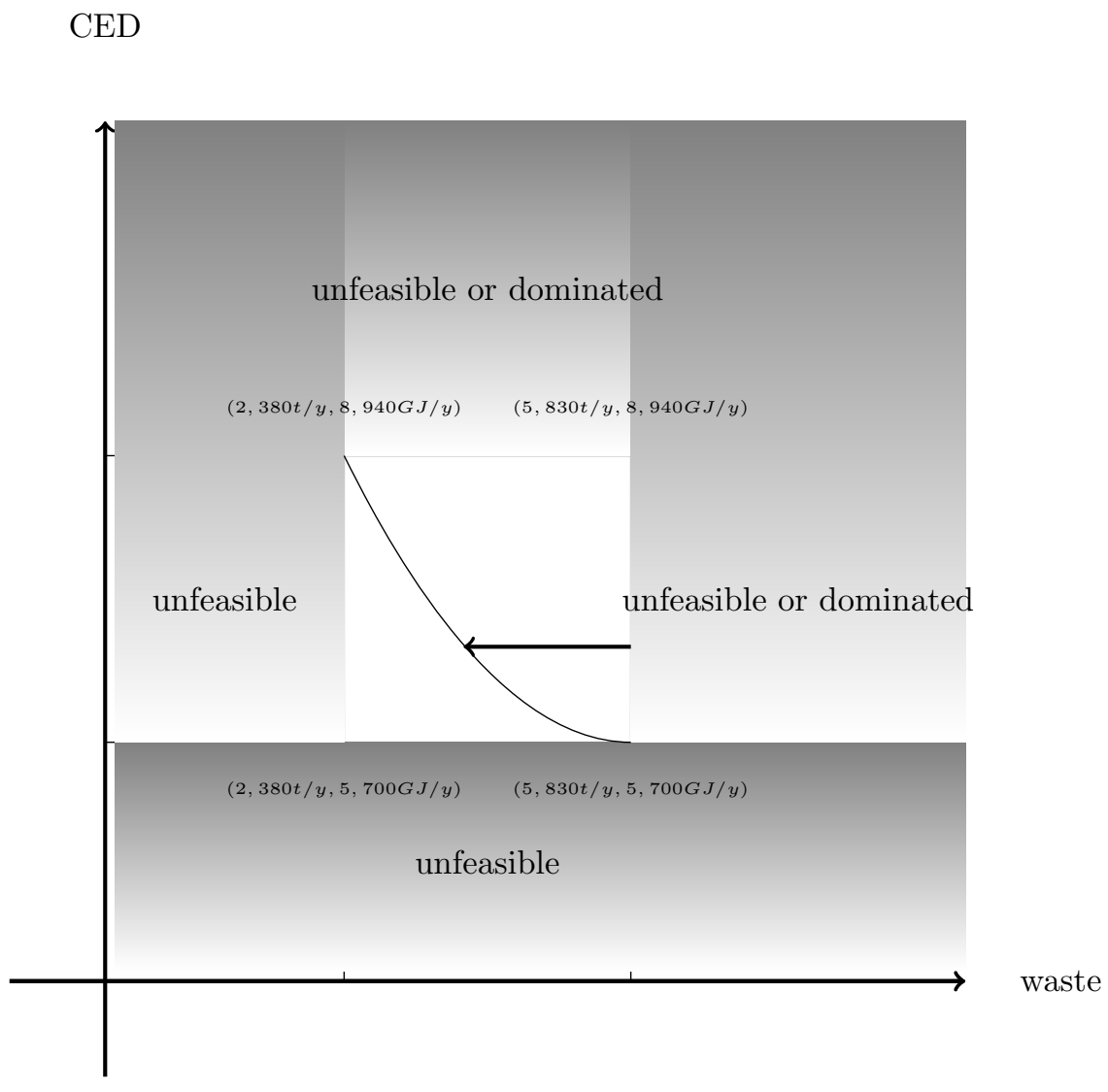

Figure 7: The proposed algorithm for a $220,000 €$ isopretium 
$(2,299 \mathrm{t} / \mathrm{y}, 9,171 \mathrm{GJ} / \mathrm{y})$

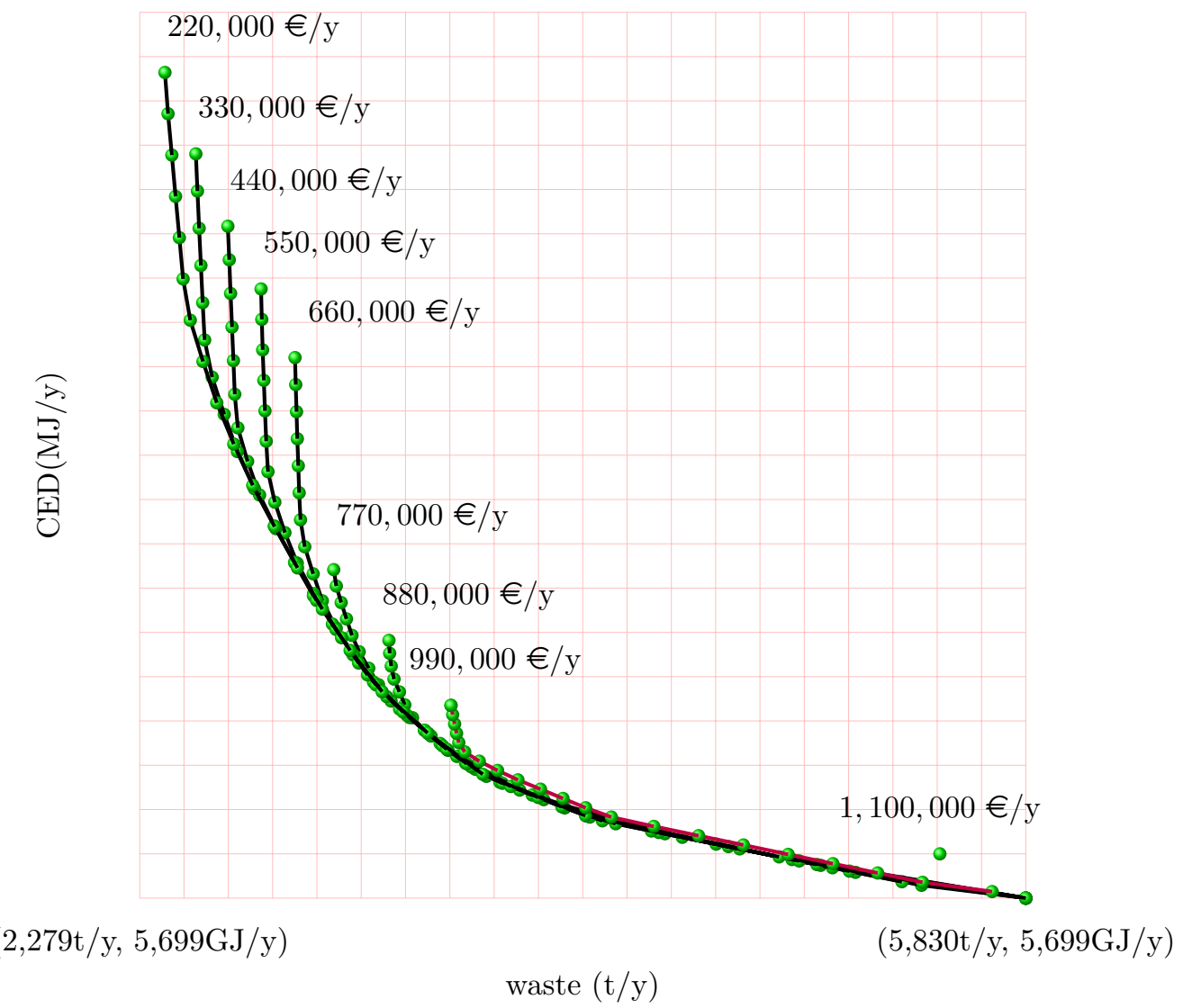

Figure 8: Eco-efficient frontier. The pairs $(a, b)$ are, respectively, the landfilled waste and CED. The number at the end of the lines are profit for the isopretiums. 


\section{References}

J. M. Bloemhof-Ruwaard, L. N. VanWassenhove, H. L. Gabel, and P. M. Weaver. Environmental life cycle optimization model for the european pulp and paper industry. Omega-International Journal of Management Science, 24(6):615-629, 1996.

J. M. Bloemhof-Ruwaard, H. Krikke, and Van Wassenhove L.N. OR models for eco-eco closed-loop supply chain optimization., volume 1 of Reverse Logistics: Quantitative Models for Closed-Loop Supply Chains. Springer-Verlag, Berlin/Heiderberg, 1st edition, 2004.

Carbonfund-Organization. http://carbonfund.org/site/pages/calculator/, 2006.

M. Fleischmann, H. R. Krikke, R. Dekker, and S. D. P. Flapper. A characterisation of logistics networks for product recovery. Omega-International Journal of Management Science, 28(6): $653-666,2000$.

M. Fleischmann, J.A.E.E. van Nunen, and B. Grave. Integrating closed-loop supply chains and spare-parts management at IBM. Interfaces, 33(6):44-56, 2003.

S. Hellweg, G. Doka, and F. Goran. Assessing the eco-efficiency of end-of-pipe technologies with the environmental cost efficiency indicator: A case study of solid waste management. Journal of Industrial Ecology, 9(4):189-203, 2005.

M.A. Huijbregts, L.J. Rombouts, S. Hellweg, R. Frischknecht, A.J. Hendriks, D. Van de Meent, A. M. Ragas, L. Reijnders, and J. Struijs. Is cumulative fossil energy demand a useful indicator for the environmental performance of products? Environmental Science Technology, 40(3), 2005.

G. Huppes and M. Ishikawa. A framework for quantified eco-efficiency analysis. Journal of Industrial Ecology, 9(4):25-41, 2005.

Y. Kobayashi, H. Kobayashi, A. Hongu, and K. Sanehira. A practical method for quantifying eco-efficiency using eco-design support tools. Journal of Industrial Ecology, 9(4):131-144, 2005. 
Stenfors S. Korhonen, P. and M. Syrjanen. Multiple objective approach as an alternative to radial projection in dea. Journal of Productivity Analysis, 20(3):305-321, 2003.

H. Krikke, J.M. Bloemhof-Ruwaard, and L. N. van Wassenhove. Current product and closed-loop supply chain design with an application to refrigerators. International Journal of Production Research, 41(16):3689-3719, 2003.

T. Kuosmanen and M. Kortelainen. Measuring eco-efficiency of production with data envelopment analysis. Journal of Industrial Ecology, 9(4):59-72, 2005.

A. J. D. Lambert. Disassembly sequencing: a survey. International Journal of Production Research, 41(16):3721-3759, 2003.

A. J. D. Lambert. Linear programming in disassembly/clustering sequence generation. Computers and Industrial Engineering, 36(4):723-738, 1999.

C. H. Papadimitrou and M. Yannakakis. On the approximability of trade-offs and optimal access to web sources. Technical report, 2001.

J. Quariguasi Frota Neto, J. Bloemhof, J.A.A.E. van Nunen, and E. van Heck. Designing and evaluating sustainable logistics networks. International Journal of Production Economics (in print), 2007.

R.W. Scholz and A. Wiek. Operational eco-efficiency: Comparing firms' environmental investments in different domains of operation. Journal of Industrial Ecology, 9(4):155-170, 2005.

R. E. Steuer and C. A. Piercy. A regression study of the number of efficient extreme points in multiple objective linear programming. European Journal of Operational Research, 162(2): 484-496, 2005.

R.E. Steuer. Random problem generation and the computation of efficient extreme points in multiple objective linear programming. Computational Optimization and Applications, 3:333$347,1994$. 
N. Walley and B. Whitehead. Its not easy being green. Harvard Business Review, 72(3), 1994.

G. Walther and T. Spengler. Impact of WEEE-directive on reverse logistics in germany. International Journal of Physical Distribution and Logistics Management, 35(5), 2005.

WEEE-directive. EU directive 2002/96/ec on waste electrical and electronic equipment. 2003.

M. Zeleny. Linear Multiobjective Programming. New York, (1974). 


\section{Publications in the Report Series Research ${ }^{*}$ in Management}

\section{ERIM Research Program: "Business Processes, Logistics and Information Systems"}

2007

India: a Case of Fragile Wireless Service and Technology Adoption?

L-F Pau and J. Motiwalla

ERS-2007-011-LIS

http://hdl.handle.net/1765/9043

Some Comments on the Question Whether Co-occurrence Data Should Be Normalized

Ludo Waltman and Nees Jan van Eck

ERS-2007-017-LIS

http://hdl.handle.net/1765/9401

Extended Producer Responsibility in the Aviation Sector

Marisa P. de Brito, Erwin A. van der Laan and Brijan D. Irion

ERS-2007-025-LIS

http://hdl.handle.net/1765/10068

Logistics Information and Knowledge Management Issues in Humanitarian Aid Organizations

Erwin A. van der Laan, Marisa P. de Brito and S. Vermaesen

ERS-2007-026-LIS

http://hdl.handle.net/1765/10071

Bibliometric Mapping of the Computational Intelligence Field

Nees Jan van Eck and Ludo Waltman

ERS-2007-027-LIS

http://hdl.handle.net/1765/10073

Approximating the Randomized Hitting Time Distribution of a Non-stationary Gamma Process

J.B.G. Frenk and R.P. Nicolai

ERS-2007-031-LIS

http://hdl.handle.net/1765/10149

Application of a General Risk Management Model to Portfolio Optimization Problems with Elliptical Distributed Returns for Risk Neutral and Risk Averse Decision Makers

Bahar Kaynar, S. Ilker Birbil and J.B.G. Frenk

ERS-2007-032-LIS

http://hdl.handle.net/1765/10151

Optimal Zone Boundaries for Two-class-based Compact 3D AS/RS

Yugang Yu and M.B.M. de Koster

ERS-2007-034-LIS

Portfolios of Exchange Relationships: An Empirical Investigation of an Online Marketplace for IT Services

Uladzimir Radkevitch, Eric van Heck and Otto Koppius

ERS-2007-035-LIS

http://hdl.handle.net/1765/10072

From Closed-Loop to Sustainable Supply Chains: The WEEE case

J. Quariguasi Frota Neto, G. Walther, J.Bloemhof, J.A.E.E van Nunen and T.Spengler ERS-2007-036-LIS

A Methodology for Assessing Eco-Efficiency in Logistics Networks J. Quariguasi Frota Neto, G. Walther, J.Bloemhof, J.A.E.E van Nunen and T.Spengler ERS-2007-037-LIS 


\section{* A complete overview of the ERIM Report Series Research in Management: https://ep.eur.n//handle/1765/1}

\section{ERIM Research Programs:}

LIS Business Processes, Logistics and Information Systems

ORG Organizing for Performance

MKT Marketing

F\&A Finance and Accounting

STR Strategy and Entrepreneurship 